\title{
Smart car parking system model for urban areas
}

\author{
Rahman Atiqur \\ Information and Communication Engineering, Chongqing University of Posts and Telecommunications, Chongqing Key \\ Lab of Mobile Communications Technology, China \\ University of Chittagong, Faculty of Engineering, Computer Science and Engineering Department, Bangladesh
}

\begin{tabular}{|c|c|}
\hline Article Info & ABSTRACT \\
\hline Article history: & This article is on the smart car parking system. In which we going to utilize \\
\hline Received Nov 2, 2020 & $\begin{array}{l}\text { the ultrasonic sensor to distinguish the vehicle and it will assist the proprietor } \\
\text { with finding a advantageous parking spot. Parking spots are significant in city }\end{array}$ \\
\hline Revised Feb 10, 2021 & urban areas. In view of the expansion in a huge number of vehicles, the \\
\hline Accepted Mar 5, 2021 & $\begin{array}{l}\text { requirement for parking spots is a need, and henceforth an earnest needs to } \\
\text { build up a system that can deal with these parking spots. To determine these }\end{array}$ \\
\hline Keywords: & $\begin{array}{l}\text { necessities we build up a system to show the empty path in the parking spots. } \\
\text { This includes a system that incorporates an ultrasonic sensor, raspberry pi } 4 \text {, }\end{array}$ \\
\hline LED display & wifi-module, and a led show outside the vehicle parking entryway. Parking \\
\hline Raspberry pi4 & $\begin{array}{l}\text { spots are observed by the staff of the concerned power. The paper incorporates } \\
\text { the subtleties of parts that are utilized and about the working of this system. }\end{array}$ \\
\hline Smart parking & The paper likewise shows that our system's looking through an ideal \\
\hline Ultrasonic sensor & opportunity to locate a free spot is more productive than some other existing \\
\hline Wi-Fi-module & system. \\
\hline
\end{tabular}

This is an open access article under the $\underline{C C B Y-S A}$ license.

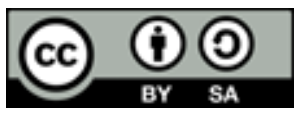

\section{Corresponding Author:}

Rahman Atiqur

School of Information and Communication Engineering

Chongqing University of Posts and Telecommunications

Key Lab of Mobile Communications Technology, Chongqing, 400065, China

Email: bulbul.cse.cu@gmail.com

\section{INTRODUCTION}

Because of the quick increment in the cars, there exists an issue for parking of cars. It prompts traffic blockage and furthermore contamination [1]. Along these lines, we have to keep up the vehicle park management to lessen the wastage of time. In the event that we see in the bigger urban areas when we visit the shopping centers or traveler places or some other business zones there emerges an issue for parking of our vehicle [2]. We essentially center on planning another smart parking system that helps drivers to discover empty parking spots in a particular parking zone. Consequently to lessen human exertion and air contamination [3]. The primary thought process is to improve each parking space with the goal that it arrives at the condition of-craftsmanship innovation. For this reason, each parking slot has been given a sensor for example Ultrasonic sensor that will distinguish the nearness of the vehicle left in the particular slot. At the point when it will recognize the vehicle it will naturally show on LED that the parking space is full. A similar message or yield is given to the mindful staff. So the staff part will manage the individual to the empty parking space [4]. This framework has numerous adaptable capacities, it can be used for a little parking space just as the enormous shopping center's staggered parking. Portions of this system incorporate Ultrasonic sensor, Wi-Fi module, LED Display, and Raspberry Pi4 gadget [5]. Based on our review from many parking spaces in Dhaka (see Figure 1), the time consuming in the parking method are caused by time consumed at doors where the driver has to get a parking card at the entry gate and has to pay parking fee at the exit gate (1 and 5) and time to find the vacant slot (2). Furthermore, in this method, there is another suffering case that might happen when the driver 
forgets to remember his/her parking slot and he/she has to walk around the area many floors to find his/her car, which is also time consuming [6].

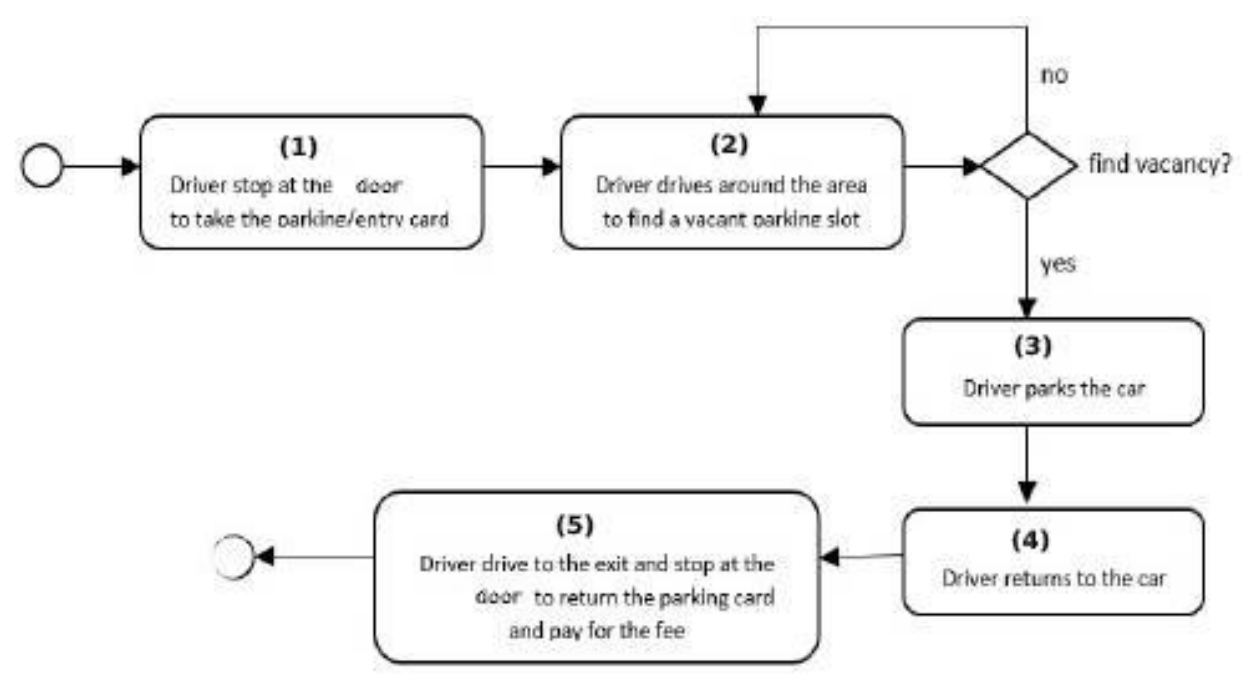

Figure 1. Existing parking system

Therefore, in this paper, we propose a solution to these problems by introducing a smart car parking system (SCPS) that is design based on Internet of Things (IoT), image processing and an iOS mobile application to give smart services such as locating available parking slots in real time, detecting car plate number, and recording position of the parked car, calculating parking fee and allowing mobile payment for the bill. In our proposed system, the doors at the entry and exit points can be removed so the bottleneck at the gates can be reduced. How the proposed system is better than the existing system graphically shows in section 4 .

In Section 2 we present our proposed Smart Car Parking System Model and Circuit diagram also describes how its component Works. Section 3 gives the result based on our proposed model and describes how these systems are more efficient compared than another existing system and Section 4 concludes the paper.

\section{PROPOSED SYSTEM}

The following Figure 2 shows the block diagram of our proposed system. The entire system is controlled by the Raspberry Pi 4 device. In these proposed systems mainly Raspberry Pi4, Ultrasonic Sensors, Wi-Fi-Module and LED Display. Each component is explained below in a detailed manner.

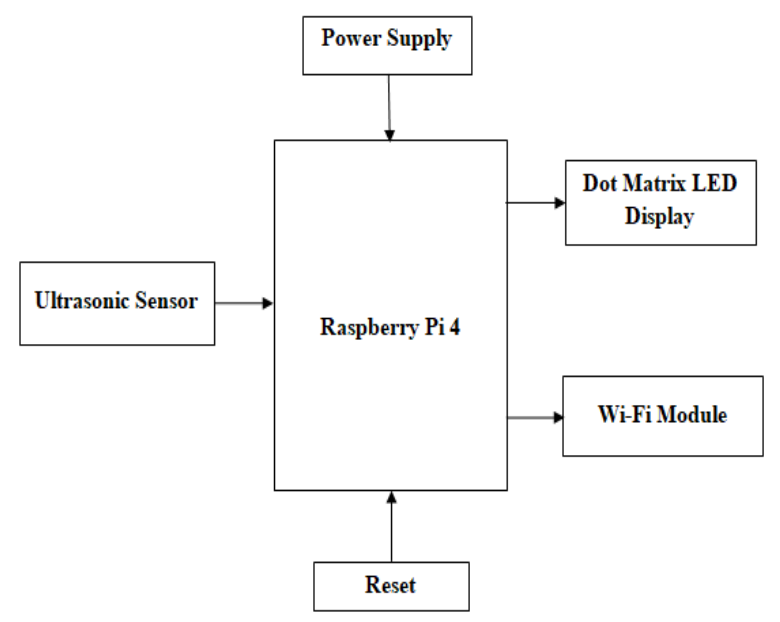

Figure 2. Block diagram of smart car parking system (SCPS) using Raspberry Pi4 


\section{a. Raspberry Pi 4}

Raspberry Pi4 is a debit card-sized single-board computer with an OS Raspbian installed [7]. Raspberry Pi4's specifications are specified in Table 1. The Raspberry collects the number of parking slots from each NodeMCU V3 and processes the data and updates the database server with a total number of vacant slots. Figure 3 shows the available interfaces in Raspberry Pi4 [7].

Table 1. Raspberry Pi 4 specifications [7]

\begin{tabular}{ll}
\hline Specifications & Values \\
\hline CPU & Broadcom BCM2711, Quad core Cortex-A72 (ARM v8) 64-bit SoC @ 1.5GHz \\
RAM & 1GB, 2GB or 4GB LPDDR4-2400 SDRAM (depending on model) \\
USB Ports & 2 USB 3.0 ports; 2 USB 2.0 ports \\
GPIO Pins & Raspberry Pi standard 40 pin \\
Uther Features & 1. HDMI - 2 × micro-HDMI ports (up to 4kp60 supported) \\
& 2. Display port - 2-lane MIPI DSI \\
& 3. Camera port - 2-lane MIPI CSI \\
& 4. Audio - 4-pole stereo audio and composite video port \\
& 5. Storage - Micro-SD card slot for loading operating system and data storage \\
& 6. Misc. - H.265 (4kp60 decode), H264 (1080p60 decode, 1080p30 encode), OpenGL \\
& ES 3.0 graphics \\
7. OS-Debian Linux 10 based
\end{tabular}

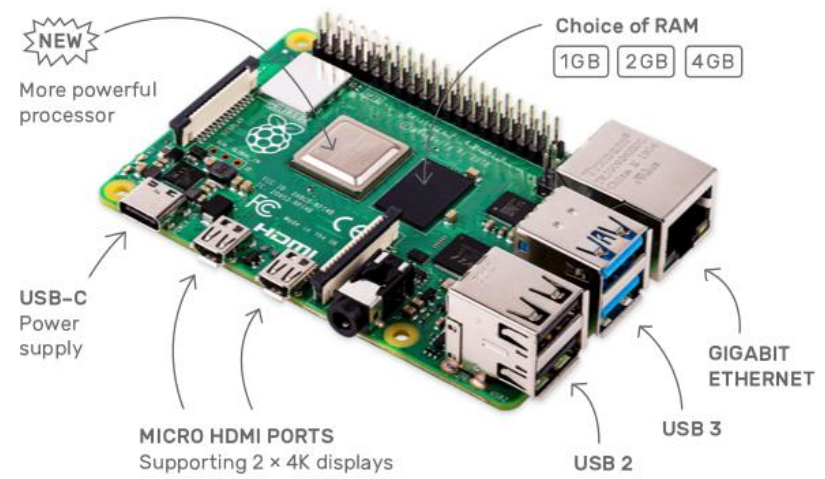

Figure 3. Raspberry Pi4 boards

\section{b. Ultrasonic sensor}

Figure 4 shows the graphics of an Ultrasonic sensor. The theory behind the ultrasonic parking sensor is based on echo-location. The frequency of the sound is so high that men cannot perceive it, which is useful because it provides correctness and remains ordinary. As sound hits a solid object, after creating an echo it is reflected back. Since the speed of sound is well-known and steady for similar conditions, it is possible to decide the distance of the object you hear an echo from by multiplying the speed of sound by half the time it takes to hear the echo (because the echo time is actually the time it takes the sound to go there and back) [8]. Technical specifications of Ultrasonic Sensors are specified in Table 2 [9].

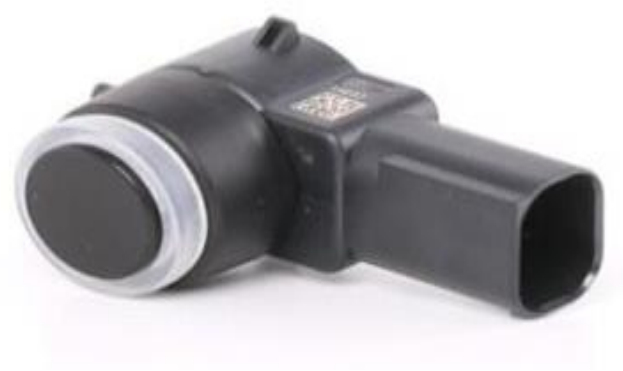

Figure 4. An ultrasonic parking sensor 
Table 2. Technical Specification of sensors [10]

\begin{tabular}{cc}
\hline Parameters & Ultrasonic Parking Sensor \\
\hline Range & $0.3 \sim 2 \mathrm{~m}$ \\
Beam-width & $\mathrm{H}>60, \mathrm{~V}>60$ degree \\
Beam Pattern & Conical \\
Frequency & $315 \mathrm{MHz} / 433 \mathrm{MHz}$ \\
Unit Cost & $30 \mathrm{INR}$. \\
\hline
\end{tabular}

\section{c. Light emitting diode (LED) display}

A LED show is a level board show that utilizes a variety of light-producing diodes as pixels for a video show [11]. Their brilliance permits them to be utilized outside where they are noticeable in the sun for store signs and bulletins. As of late, they have additionally gotten ordinarily utilized in goal signs on open transport vehicles, just as factor message signs on parkways. Driven presentations are fit for giving general enlightenment notwithstanding visual showcases, as when utilized for stage lighting or other beautifying (instead of instructive) purposes [12]. LED showcases can offer higher complexity proportions than a projector and are in this way an option in contrast to conventional projection screens, and they can be utilized for huge, continuous (without a noticeable lattice emerging from the bezels of individual presentations) video dividers. Miniaturized scale LED shows are LED shows with littler LEDs, which presents huge improvement challenges [13], [14].

LED Display (light-emitting diode show) is a screen show innovation that utilizes a board of LEDs as the light source. Right now, an enormous number of electronic gadgets, both little and huge, use LED show as a screen and as an association medium between the client and the framework. Present-day electronic gadgets, for example, cell phones, TVs, tablets, PC screens, workstations screens, and so on, utilize a LED show to show their yield.

LED Display is one of the principal screens shows that are as a rule economically utilized. The greatest favorable position of the LED show is its productive and low-vitality utilization, which is particularly required for handhelds and chargeable gadgets, for example, cell phones and tablets. A LED show comprises various LED boards that, thus, comprise of a few LEDs. LEDs have various favorable circumstances over other lighttransmitting sources that can be utilized then again. Besides being power effective, LEDs produce more splendor and more noteworthy light force. LED-Display is not the same as the vacuum fluorescent showcase utilized in some purchaser hardware, for example, vehicle sound systems, videocassette recorders, and so forth., and, consequently, these two ought not to be mistaken for one another [15], [16]. Figure 5 shows the pin diagram of a 7 segment display board.
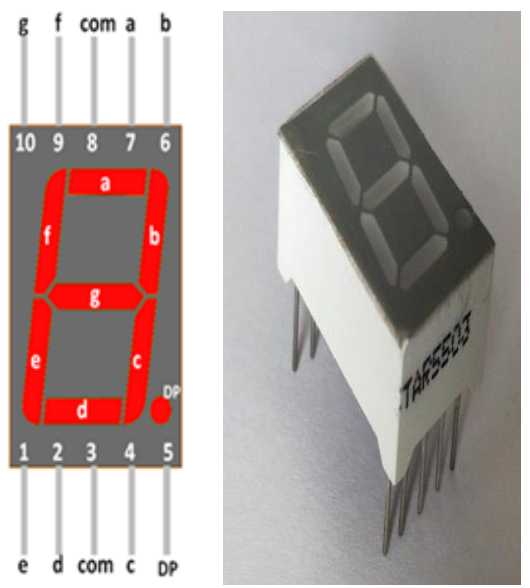

Figure 5. 7 Segment display pin diagram

\section{d. Wi-Fi-module}

The ESP8266 Wi-Fi Module shown in Figure 6 is an independent System on a Chip (SOC) with an incorporated TCP/IP protocol stack that can give any microcontroller access to your Wi-Fi network. The ESP8266 is able to do either facilitating an application or offloading all Wi-Fi networking capacities from another application processor [17]. Each ESP8266 module comes pre-modified with an AT order set firmware, 
which means you can essentially attach this to your Raspberry Pi4 gadget and get about as much Wi-Fi-capacity as a Wi-Fi Shield offers. The ESP8266 associates with the outside world utilizing the serial port. The Pi controls it and moves information utilizing an arrangement of AT orders. These were normally used to control modems and other correspondence gear despite everything being utilized in cell phone modems. Generally, the ESP8266 resembles a modem that interfaces with $\mathrm{Wi}-\mathrm{Fi}$. The ESP8266 module is a very savvy board with an enormous, and ever-developing, network.

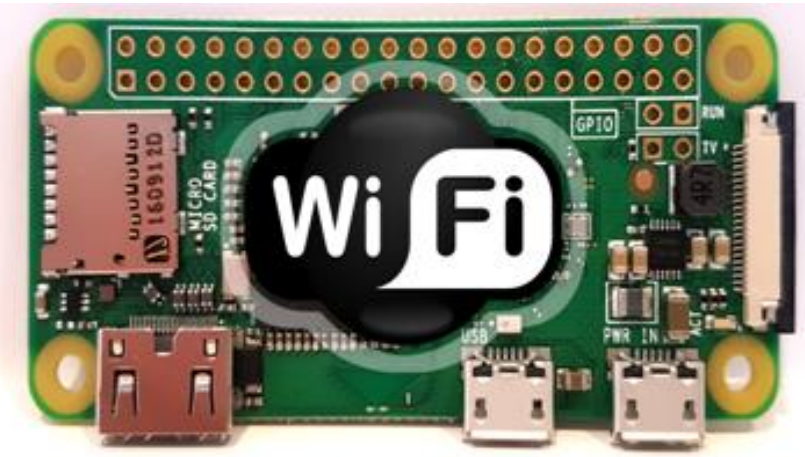

Figure 6. Wi-Fi-module

\section{e. Circuit diagram of our proposed system}

In this circuit, ultrasonic sensors are utilized for each parking slot. These ultrasonic sensors are associated with the Raspberry Pi4 pins. The LEDs are associated with the Digital I/O pins which give shading RED and GREEN. The reading will be shown on the LED which will educate the guests about the free space accessible inside the parking. At the point when the slot will be empty then the ultrasonic sensor collector won't get any sign. Thus a GREEN light will sparkle. In the event that any sign is gotten by the ultrasonic sensor beneficiary, at that point it will be contrasted with the edge esteem, and in the event that it is more than the limit esteem, at that point the RED light will shine [18]. This procedure will be like every other space, and at whatever point a vehicle enters or leaves the parking region, the information is ceaselessly refreshed. At the point when a vehicle enters or leaves the parking slots, the separate LED will gleam right away. On the off chance that any of the parking slots are involved, at that point, an instant message will be shown on LED and your versatility about the amount more space is empty [18]-[20]. All of the things are graphically shown in Figure 7.

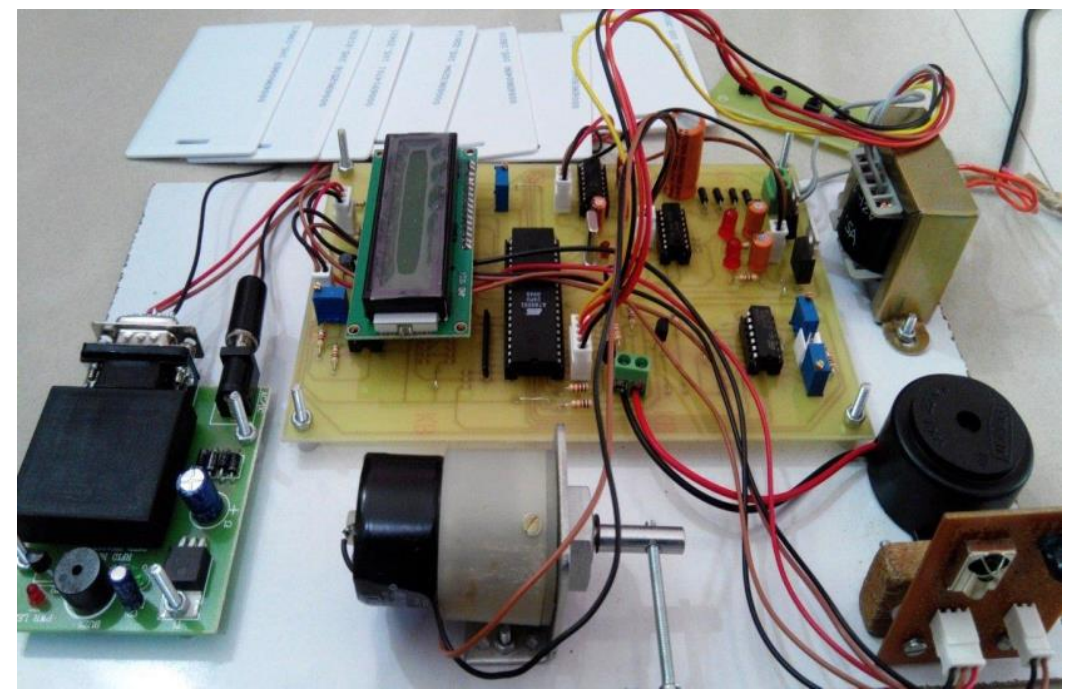

Figure 7. The circuit diagram of the proposed system 


\section{RESULTS AND DISCUSSION}

\subsection{Database}

Here, in this thesis we are using a live dataset of cars and it is in store in MySQL.

\subsection{Experimental setup}

\subsubsection{Hardware requirement \\ a. Raspberry Pi 4 \\ b. Ultrasonic Sensor \\ c. Wi-Fi Module \\ d. Web Camera}

\subsubsection{Software requirements}

a. The system is built using the Java framework on Windows platform

b. The Net beans IDE are used as a development tool

c. For Database using MySQL

d. MATLAB Simulation Software

\subsection{Expected result}

In this subsection discussed the experimental result of the proposed system. Table 3 and Figure 8 represent the comparative analysis of time required for smart parking in existing and proposed systems. From the figures it is clear that the proposed system is faster than the existing system to park the car.

Table 3. Required time and distance comparison

\begin{tabular}{cccccc}
\hline $\begin{array}{c}\text { Distance } \\
\begin{array}{c}\text { Travelled (in } \\
\text { meters) for } \\
\text { Existing System }\end{array}\end{array}$ & $\begin{array}{c}\text { Time Required } \\
\text { in minute) for } \\
\text { Existing } \\
\text { System }\end{array}$ & $\begin{array}{c}\text { Existing } \\
\text { System }\end{array}$ & $\begin{array}{c}\text { Distance Travelled } \\
\text { (in meters) for } \\
\text { SCPS System }\end{array}$ & $\begin{array}{c}\text { Time Required } \\
\text { (in minute) for } \\
\text { SCPS }\end{array}$ & SCPS \\
\hline 0 & 10 & Success & 0 & 10 & Success \\
160 & 20 & Success & 50 & 20 & Success \\
220 & 30 & Success & 40 & 30 & Success \\
290 & 40 & Success & 30 & 40 & Success \\
395 & 50 & Success & 35 & 50 & Success \\
\hline
\end{tabular}

Now from the tabular value the following assessed chart Figure 8 it plainly shows that our system will be progressively more effective than the other existing system where the existing system was manual based or some other online systems which are used by older devices compared to our proposed system. From Figure 7, it is clear our proposed smart car parking system requires less than an ideal opportunity to scan for a free spot when contrasted with that of ordinary pursuit. In a typical inquiry client sets aside part of the effort to discover the accessible space. Be that as it may, in our proposed strategy we have a choice of pre booking, which spares time [21]-[25].

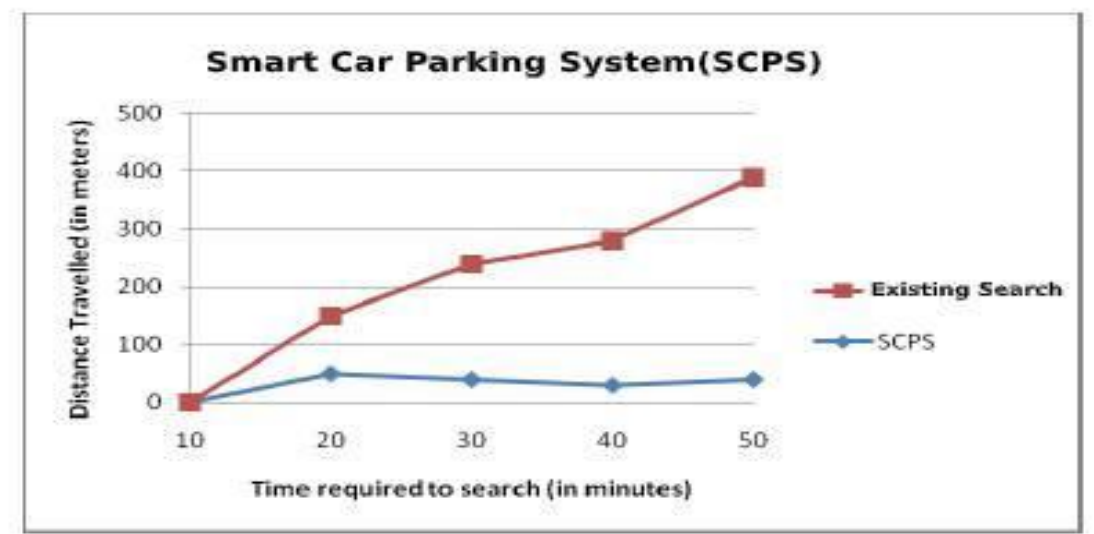

Figure 8. Performance comparison with existing system 


\section{CONCLUSION}

In this article, we brought out how the parking issue in jam-packed spots can be handled in an allaround concocted way. It is a very time-productive technique, it causes the guests to discover the accessibility of a parking slot. It likewise empowers urban communities to build up a completely progressed and smart transportation system for simple access to parking. This system will dodge wastage of fuel, thus less contamination and traffic blockage can be decreased. It assists drivers with finding empty parking spaces near them. Looking through the time of our proposed smart car parking system requires less contrast with some other existing system. It very well may be generally utilized in shopping centers and business structures or swarmed regions where countless individuals can share a parking area. This smart car parking system will diminish time-wastage, long lines, pressure, and increment the effectiveness of the parking system. Notwithstanding this, it expands wellbeing and gives a without hustle condition. It diminishes time utilization. So by actualizing our smart car parking system utilizing ultrasonic sensors we can deal with our time and vehicles can be left without any problem.

\section{ACKNOWLEDGEMENTS}

I would like to convey my heartfelt gratitude towards my guide, Professor Dr. Yun Li for his constant guidance, encouraging help, and inspiring words. I am thankful for the School of Information and Communications Engineering for their support.

\section{REFERENCES}

[1] V. Hans, P. S. Sethi, J. Kinra, "An approach to IoT based car parking and reservation system on Cloud," 2015 International Conference on Green Computing and Internet of Things (ICGCIoT), 2015, doi: https://doi.org/10.1109/ICGCIoT.2015.7380487.

[2] M. S R, “Automatic Smart Parking System using Internet of Things (IoT),” International Journal of Scientific and Research Publications, vol. 5, no. 12, 2015.

[3] D.J. Bonde, R. Shende, K. Gaikwad, A. Kedari and A. Bhokre, "Automated car parking system commanded by android application," International Conference on Computer Communication and Informatics, vol. 5, no. 3, 2014 pp. 3001-3004, 2014.

[4] P. Parkhi, S. Thakur and S. Chauhan, "RFID-based Parking Management System," International Journal of Advanced Research in Computer and Communication Engineering, vol. 3, no. 2, 2014.

[5] Rindhe, Chaitanya, Mahesh Kamthe, B. N. Nishanth, Lalit Kumar, and Kanishka Bisen, "Smart Car Parking System using IR Sensor," International Journal for Research in Applied Science \& Engineering Technology (IJRASET), vol. 8, no. v, May 2020.

[6] Lookmuang, R., Nambut, K., \& Usanavasin, S. "Smart parking using IoT technology," In 2018 5th International Conference on Business and Industrial research (ICBIR), IEEE, 2018, pp. 1-6.

[7] Raspberry Pi 4 Documentation, [Online] Available: https://www.raspberrypi.org/.

[8] A. Dimitrov and D. Minchev, "Ultrasonic sensor explorer," 2016 19th International Symposium on Electrical Apparatus and Tehnologies (SIELA), Bourgas, 2016, pp. 1-5.

[9] Parking Sensors, 2021, [Online] Available: https://www.parkingsensors.co.uk/page/technical-specifications.

[10] Atif, Y., Ding, J., \& Jeusfeld, M. A. "Internet of things approach to cloud-based smart car parking," Procedia Computer Science, vol. 98, pp. 193-198, 2016.

[11] Patel, C., Swami, M., Saxena, P. and Shah, S. "Rotary automated car parking system," International Journal of Engineering Science and Innovative Technology (IJESIT), vol. 4, no. 2, pp. 408-415, 2015.

[12] Nandyal, S., Sultana, S., \& Anjum, S. "Smart car parking system using arduino uno," International Journal of Computer Applications, vol. 169, no. 1, pp. 13-18, 2017.

[13] Kotb, A. O., Shen, Y. C., \& Huang, Y. "Smart parking guidance, monitoring and reservations: a review," IEEE Intelligent Transportation Systems Magazine, vol. 9, no. 2, pp. 6-16, 2017.

[14] Chippalkatti, P., Kadam, G., \& Ichake, V. "I-SPARK: IoT Based Smart Parking System," In 2018 International Conference On Advances in Communication and Computing Technology (ICACCT), IEEE, pp. 473-477, Feb 2018.

[15] Rahman Atiqur, Yun Li, "Automated Smart Car Parking System Using Raspberry Pi 4 and iOS Application," International Journal of Reconfigurable and Embeded Systems (IJRES), vol. 9 no. 3, pp 229-234, 2020, doi: http://doi.org/10.11591/ijres.v9.i3.pp229-234.

[16] Rahman Atiqur, Ali Md Liton, \& Guangfu Wu, "Content Caching Strategy at Small Base Station in 5G Networks with Mobile Edge Computing," International Journal of Science and Business, vol. 4, no. 4, pp. 104-112, 2020, doi: https://doi.org/10.5281/zenodo.3746233.

[17] Rahman Atiqur, Guangfu Wu, Ali Md Liton, "Mobile edge computing for internet of things (IoT): security and privacy issues," Indonesian Journal of Electrical Engineering and Computer Science (IJEECS), vol. 18 no. 3 , pp.1486-1493, doi: http://doi.org/10.11591/ijeecs.v18.i3.pp1486-1493.

[18] Rahman Atiqur, Yun Li, Ali Md Liton, "Automated Smart Car Parking System Using Internet of Things (IoT) Technology for Smart Cities Demand," North American Academic Research, vol. 3, no. 8, pp. 7-19, doi: https://doi.org/10.5281/zenodo.3978756. 
[19] Liton, Ali Md, Rahman Atiqur, and Hosen Md Shawkat, "High-efficiency and Low-overhead Selfish Node Detection Algorithm in Opportunistic Networks," International Journal of Science and Business, vol. 4, no. 2, pp. 281-289, 2020.

[20] Rahman Atiqur, Yun Li, "RFID Based Smart Car Parking Management System Using Internet of Things (IoT)," IAES International Journal of Robotics and Automation (IJRA), vol. 10, no. 1, pp. 10-20, 2021.

[21] Parmar, Janak, Pritikana Das, and Sanjaykumar M. Dave, "Study on demand and characteristics of parking systems in urban areas: A review," Journal of Traffic and Transportation Engineering (English Edition), vol. 7, no. 1, pp. 111-124, 2020.

[22] Shail, Shubhda, Priyanka Yadav, Kavita Pawar, and Sagar Salunke, "i-Parker-A New Smart Car Parking System," International Research Journal of Engineering and Technology (IRJET), vol. 6, no. 5, pp. 125-128, 2019.

[23] Gopal, D. Ganesh, M. Asha Jerlin, and M. Abirami, "A smart parking system using IoT," World Review of Entrepreneurship, Management and Sustainable Development, vol. 15, no. 3, pp. 35-345, 2019.

[24] Md Abdullah Al Maruf, S. Ahmed, Md. Tangir Ahmed, A. Roy, Z. F. Nitu, "A proposed model of integrated smart parking solution for a city," 2019 International Conference on Robotics, Electrical and Signal Processing Techniques (ICREST), IEEE, 2019.

[25] Tandon, Righa, and P. K. Gupta, "Optimizing smart parking system by using fog computing," International Conference on Advances in Computing and Data Sciences, Springer, Singapore, 2019.

\section{BIOGRAPHIES OF AUTHORS}

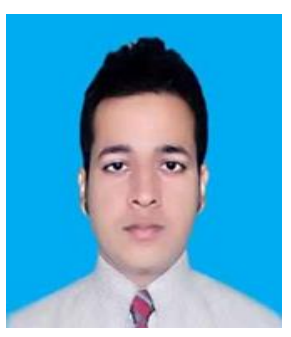

Mr. Rahman Atiqur received his Bachelor of Science (B.Sc) and Master of Engineering (M.Engg.) degree from the Department of Computer Science and Engineering at University of Chittagong, Chittagong, Bangladesh. In profession, he worked in the Department of Computer Science and Engineering, University of Chittagong, Bangladesh as an Assistant Professor since April 2016.Formar he was a lecturer in the Department of Computer Science and Engineering, University of Chittagong, Bangladesh. He is now conducting his Ph.D. research works under the Chinese Government Scholarships (CGS) Program at Chongqing University of Posts and Telecommunications, Chongqing, China. His current research interest lies in the field of edge computing based IoT systems. 